\title{
Fatal Pneumothorax Secondary to Duodenal Perforation After Endoscopic Retrograde Cholangiopancreatography
}

\author{
Muhammad Asim Rana ${ }^{\mathrm{a}}$, Murid Hussain ${ }^{\mathrm{b}}$, Sohail Iqbal ${ }^{\mathrm{c}, \mathrm{d}}$, Omer E Ramadan ${ }^{\mathrm{a}}$, Sameh Ashmawi \\ Mohammed A T Al-Dabbagh ${ }^{\mathrm{c}}$, Mohammed A Cheema ${ }^{\mathrm{c}}$, Ahmed F Mady ${ }^{\mathrm{a}}$
}

\begin{abstract}
Endoscopic retrograde cholangiopancreatography (ERCP) is a widely accepted diagnostic and therapeutic modality for extrahepatic biliary and pancreatic pathologies. Although minimally invasive and day case procedure, it is not free from complications including bleeding, perforation, cholangitis and pancreatitis. Some of these complications, if left undiagnosed or poorly managed can become life threatening such as pneumothorax secondary to duodenal perforation. Hence, recognition and understanding of potential complications of ERCP is vital. We report a case of rapidly fatal duodenal perforation with pneumoperitoneum, pneumoretroperitoneum, bilateral pneumothoraces, pneumomediastinum, and subcutaneous emphysema causing hemodynamic compromise.
\end{abstract}

Keywords: ERCP; Pneumothorax; Pneumoperitoneum; Pneumoretroperitoneum; Pneumomediastinum; Surgical emphysema

\section{Introduction}

Towards the end of last century, widespread use of endoscopic retrograde cholangiopancreatography (ERCP) has been instrumental in the management of patients with extra hepatic biliary tract and pancreatic diseases. Bleeding, perforation, cholangitis, and pancreatitis are the major complications of this invasive procedure with an overall mortality rate of about $1 \%$ [1]. Post-procedure pneumoperitoneum, pneu-

\footnotetext{
Manuscript accepted for publication February 18, 2014

${ }^{a}$ Department of Intensive Care Medicine, King Saud Medical City, Riyadh, Kingdom of Saudi Arabia

${ }^{b}$ Department of Internal Medicine, Tameside General Hospital, Ashton under Lyne, OL6 9RW, England, UK

${ }^{\mathrm{c}}$ Department of Radiology, Colchester General Hospital, Colchester, CO4 5JL, England, UK

${ }^{\mathrm{d}}$ Corresponding author: Sohail Iqbal, Radiology Department, Colchester General Hospital, Colchester, CO4 5JL, England, UK, Email: drsohailiqbal@yahoo.com
}

doi: http://dx.doi.org/10.14740/jmc1700w momediastinum and subcutaneous emphysema indicate an iatrogenic duodenal perforation. It is rare but serious complication having up to $23 \%$ mortality rate [2]. Changes in vital signs, dyspnea and decreasing oxygen saturation, especially following (pre-cut) sphincterotomy, should be considered a sensitive indicator of perforation or pneumothorax.

\section{Case Report}

A 90 years old lady underwent ERCP for biliary pancreatitis as an elective procedure. During the procedure, she was found to have duodenal diverticulum. Papillotomy with the drainage of the sludge was performed. Post procedure patient was shifted to emergency room due to radiographic evidence of surgical emphysema in the face, head and neck and chest region (Fig. 1a). She was intubated and transferred to intensive care unit (ICU) because of rapid hemodynamic compromise. After initial management contrast enhanced computerized tomography (CECT) was performed which revealed extensive surgical emphysema encompassing the whole body (Fig. 1b) along with air in all body cavities i.e., bilateral pneumothorax, pneumomediastinum (Fig. 2a), pneumoperitoneum and pneumoretroperitoneum (Fig. 2b). Minimal contrast leakage was noticed around the duodenal area. A second look endoscopy failed to show any duodenal diverticulum or evidence of perforation at any other level. Patient succumbed to the overwhelming shock and multiorgan failure in-spite of the enhanced multidisciplinary support.

\section{Discussion}

Since its introduction in 1968, ERCP has become a commonly performed endoscopic procedure [3]. The diagnostic and therapeutic role of ERCP has been well demonstrated for a variety of disorders, such as the management of choledocholithiasis, the diagnosis and management of biliary and pancreatic neoplasms, and the postoperative management of biliary peri-operative complications [4]. ERCP has proved superior to its diagnostic counterpart magnetic resonance 


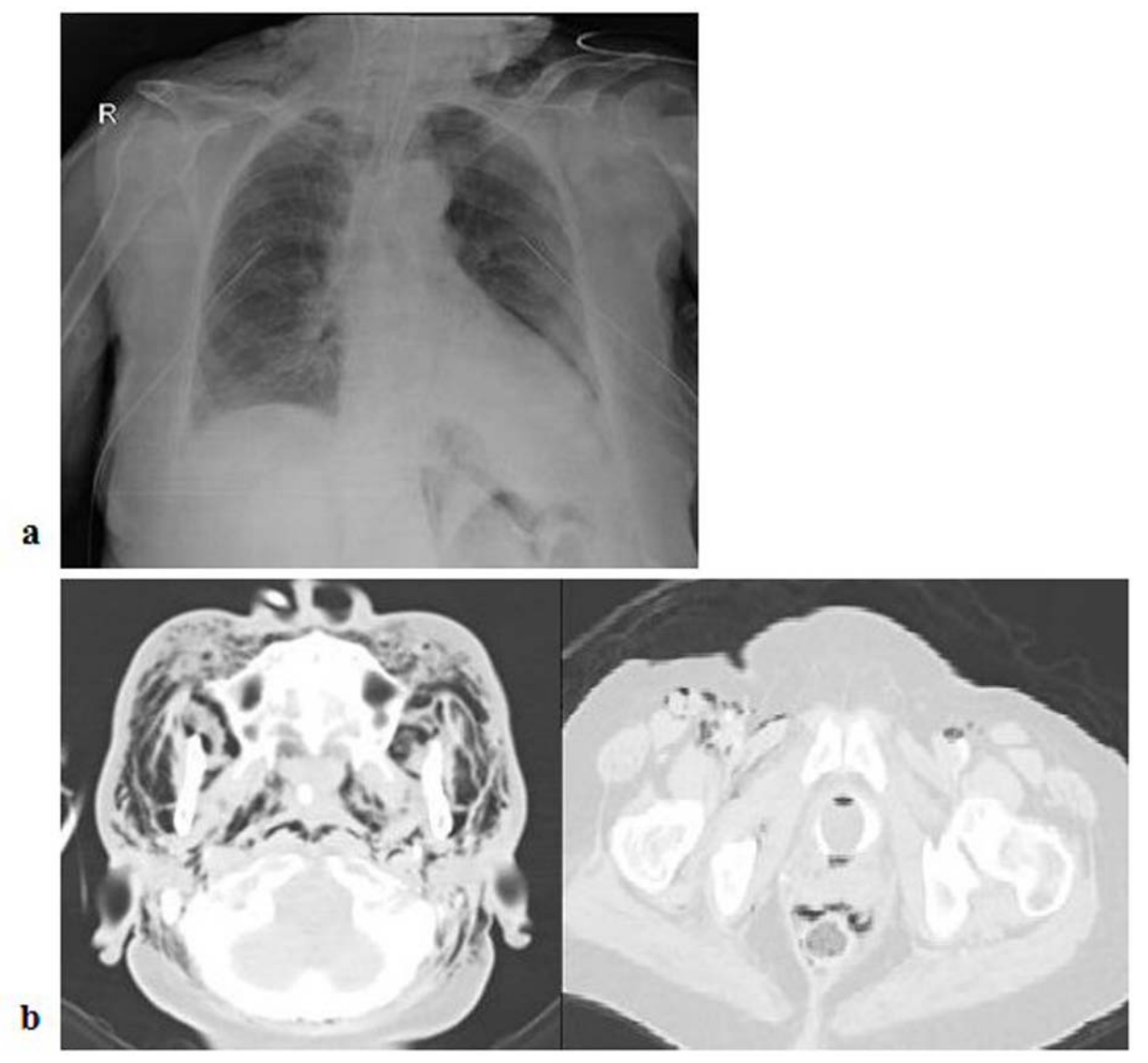

Figure 1. a) Chest X-ray showing surgical emphysema in the neck region; b) CECT revealing surgical emphysema encompassing whole body.

cholangiopancreatography (MRCP) in its therapeutic uses and to its therapeutic competitor laparoscopic cholecystectomy (with or without intraoperative cholangiography) in diagnostic sphere.

Bleeding, perforation, cholangitis, and pancreatitis are some common complications of this invasive procedure [5]. Portal venous or systemic air embolism is a very rare complication [6]. Post ERCP pneumothorax is suggested to be an exceptional complication that can occur at any age and, is usually right sided or bilateral. It is typically associated with the presence of retroperitoneal, mediastinal, subcutaneous and frequently intra-peritoneal air [7].

The main risk factors, for ERCP related pneumothorax include sphincterotomy (precut), presence of juxta-papillary diverticula, sphincter of oddi dysfunction, dilated bile duct, papillary stenosis, age of the patient and extended procedure duration [8]. Perforation can be classified according to mechanism of injury and anatomical location as follows in descending order of severity: Lateral or medial duodenal wall perforation (Type I), Peri-Vaterian (sphincter of Oddi) injuries (Type II), Wire/basket related distal bile duct injuries (Type III) and Retroperitoneal air alone (Type IV) which is probably related to the use of compressed air to maintain patency of the duodenal lumen resulting in intramural and extra-luminal air diffusion [5].

During ERCP, air can reach pleural cavity through duodenal rupture porous diaphragm syndrome [9] or alveolar rupture. In most cases, pneumothorax coexists with pneumoretroperitoneum. This finding indicates that air enters the retroperitoneal space after interruption of the duodenal barrier, through a site of perforation or a site of low resistance. Subsequently, air transfers from the retroperitoneal space to the peritoneum, subcutaneous tissue, mediastinum, and finally pleural space. Passage of air from the mediastinum to the pleural space demands a rupture of the parietal pleura. The retroperitoneal perforation is mainly caused by sphincterotomy and can be differentiated from intra-peritoneal rupture by the absence of peritoneal signs.

Congenital or acquired porous diaphragm may allow passage of air and fluids between abdominal and thoracic cavities. However, absence of concomitant intraperitoneal air in some patients with ERCP associated pneumothorax does not support this hypothesis as a central mechanism.

Alveolar rupture may occur due to increased intra-thoracic pressure in patients who poorly tolerate endoscopic procedures, in anxious patients with continuous movements 

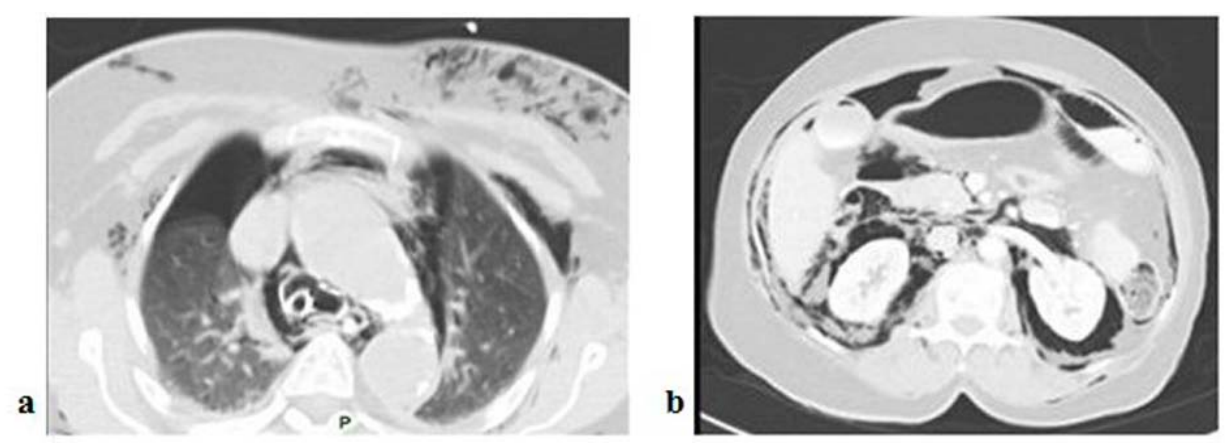

Figure 2. a) CECT with bilateral pneumothoraces and pneumomediastinum; b) CECT showing pneumoperitoneum and pneumoretroperitoneum.

or retching and can lead to the development of tension pneumothorax. In these cases one may not find free air in retroperitoneal space, intraperitoneal cavity, or mediastinum. The clinical presentation depends upon the amount of escaped air and its extension into the adjacent tissues and cavities. Most common signs and symptoms are abdominal distention, abdominal/chest pain, tachycardia, dyspnea, and subcutaneous emphysema and may become manifest either during or after ERCP [10].

Roentgenogram can show presence and accumulation of air and is sufficient in majority of cases whereas oral contrast studies/CECT abdomen may show retroperitoneal contrast leakage in complicated cases. Retroperitoneal perforation is usually not visible with endoscope.

Because of the rarity of this complication, large case series or controlled studies are not available with respect to the optimal treatment; however, there are increasing number of case reports that indicates that a non-surgical approach can be followed. Conservative management consists of administration of intravenous antibiotics, parenteral nutrition withholding of oral feeding, and pleural drainage. Patient should be carefully observed and any concern about the clinical deterioration should lead to prompt surgical consultation.

Duodenal perforation secondary to sphincterotomy has been treated with endoscopic clips or fibrin glue [11]. Signs of acute peritoneal irritation with or without sepsis, large contrast extravasation, and presence of intra- or retroperitoneal fluid collections and failure of initial conservative management are the indications for surgical closure of the leak [12].

Iatrogenic post-ERCP perforation triggering a cascade of retroperitoneal, intraperitoneal, mediastinal and subcutaneous air and culminating into hemo-dynamically unstable pneumothorax is a rare but potentially fatal complication. The most crucial part of the management is the early detection of this dreadful complication.

\section{Acknowledgement}

We are greatly indebted to Dr. Shagufta Jabeen, (Clinical Fel- low, Royal Manchester Children Hospital, Manchester) and Mr. Andy Richardson (Library \& E-learning Lead CHUFT, Colchester) for their help and support provided during preparation of this manuscript.

\section{References}

1. Christensen M, Matzen P, Schulze S, Rosenberg J. Complications of ERCP: a prospective study. Gastrointest Endosc. 2004;60(5):721-731.

2. Kwon CI, Song SH, Hahm KB, Ko KH. Unusual complications related to endoscopic retrograde cholangiopancreatography and its endoscopic treatment. Clin Endosc. 2013;46(3):251-259.

3. Kwon W, Jang JY, Ryu JK, Kim YT, Yoon YB, Kang MJ, Kim SW. Proposal of an endoscopic retrograde cholangiopancreatography-related perforation management guideline based on perforation type. J Korean Surg Soc. 2012;83(4):218-226.

4. Maple JT, Ben-Menachem T, Anderson MA, Appalaneni V, Banerjee S, Cash BD, Fisher L, et al. The role of endoscopy in the evaluation of suspected choledocholithiasis. Gastrointest Endosc. 2010;71(1):1-9.

5. Stapfer M, Selby RR, Stain SC, Katkhouda N, Parekh D, Jabbour N, Garry D. Management of duodenal perforation after endoscopic retrograde cholangiopancreatography and sphincterotomy. Ann Surg. 2000;232(2):191198.

6. Siddiqui J, Jaffe PE, Aziz K, Forouhar F, Sheppard R, Covault J, Bonkovsky HL. Fatal air and bile embolism after percutaneous liver biopsy and ERCP. Gastrointest Endosc. 2005;61(1):153-157.

7. Andriulli A, Loperfido S, Napolitano G, Niro G, Valvano MR, Spirito F, Pilotto A, et al. Incidence rates of postERCP complications: a systematic survey of prospective studies. Am J Gastroenterol. 2007;102(8):1781-1788.

8. Schepers NJ, van Buuren HR. Pneumothorax following ERCP: report of four cases and review of the literature. Dig Dis Sci. 2012;57(8):1990-1995.

9. Sampaziotis F, Wiles A, Shaukat S, Dickinson RJ. Bi- 
lateral Pneumothorax and Subcutaneous Emphysema following Endoscopic Retrograde Cholangiopancreatography: A Rare Complication. Diagn Ther Endosc. 2010;2010.

10. Al-Ashaal YI, Hefny AF, Safi F, Abu-Zidan FM. Tension pneumothorax complicating endoscopic retrograde cholangiopancreatography: case report and systematic literature review. Asian J Surg. 2011;34(1):46-49.
11. Machado NO. Management of duodenal perforation post-endoscopic retrograde cholangiopancreatography. When and whom to operate and what factors determine the outcome? A review article. JOP. 2012;13(1):18-25.

12. Williams EJ, Taylor S, Fairclough P, Hamlyn A, Logan RF, Martin D, Riley SA, et al. Risk factors for complication following ERCP; results of a large-scale, prospective multicenter study. Endoscopy. 2007;39(9):793-801. 